\title{
The Effect of Different Boundary Support Condition and Reinforcement Orientation on Impact Resistance of Light Weight Oil Palm Shells Reinforced Geogrid Concrete Slab
}

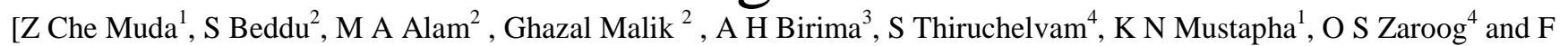
$\mathrm{Usman}^{1}$ ]

\begin{abstract}
This paper investigate the performance of lightweight oil palm shells concrete (OPS-LWC) slab with geogrid reinforcement of three OPS content to cement weight ratio of $0.45,0.50$ and 0.60 . Slabs of $300 \mathrm{~mm} \times 300 \mathrm{~mm}$ size with thickness of $20 \mathrm{~mm}, 30 \mathrm{~mm}$ and $40 \mathrm{~mm}$ were casted with different geogrid orientation and with different support boundary conditions are subjected to low impact projectile test. A self-fabricated dropweight impact test rig with a steel ball weight of $1.2 \mathrm{~kg}$ drop at $1 \mathrm{~m}$ height has been used in this research work. The main variables for the study is to find the relationship of the impact resistance against the support boundary conditions and geogrid reinforcement orientation for various OPS content. Test results indicate that for 0.45 OPS content, the four support boundary conditions for control sample increased the impact resistance under service (first) limit crack up to 5.9 times and at ultimate limit crack up to 20.1 times against the control sample with 2 supports without geogrid. A good linear relationship has been established between first and ultimate crack resistance against the slab thickness. The orientation of the geogrid has minor significant to the crack resistance of the OPS concrete slab. OPS geogrid reinforced slab has a good crack resistance properties that can be utilized as a sustainable impact resistance construction materials.
\end{abstract}

Keywords-Impact resistance, oil palm shell concrete, geogrid, impact energy,.

\section{Introduction}

The search of sustainable green materials for the construction industry has reached its critical time to mitigate the negative impact of the climatic change. It is critical to study the impact strength characteristics and assess its performance for eco-green construction materials for various potential use in the building industry.

There is lack of research investigation been carried out on impact resistance of light weight geogrid reinforced concrete. Impact resistance represents the ability of concrete to withstand repeated blows and absorb energy without adverse effect to cracking and spalling. Impact scenario can also be classified into low velocity impact and high velocity impact. Gopalartnam and Shah [1] measured the performance of impact resistance to analyse different compositions of materials.

After detailed observation and interpretation of results, they concluded that the projectile impact effect is based on

\footnotetext{
${ }^{l}$ Centre of Forensic Engineering, Universiti Tenaga Nasional, Malaysia ${ }^{2}$ Student, Universiti Tenaga Nasional, Malaysia

${ }^{3}$ Centre of Sustainable Technology and Environment, Universiti Tenaga Nasional, Malaysia

${ }^{4}$ Centre of Innovation and Design, Universiti Tenaga Nasional,,Malaysia
}

number of factors such as configurations of the loading, geometry of specimen, compliance of the tests system, rate of loading and the prescribed criteria of failure. Mahmoud et. al [2] in 2010 mentioned that, out of all these testing options, the drop weight impact test which is recommended by the ACI Committee 544 [3] is the simplest.

The review paper on impact resistance on concrete target has been published by Zakaria Che Muda et al [4]. Impact resistance of oil palm shells lightweight concrete slab with bamboo fibers has been studied by Zakaria Che Muda et al. The results indicate that $2 \%$ volume fraction of bamboo fibers has an optimal performance for first crack resistance and ultimate crack resistance [5]. Zakaria Che Muda et al has also studied the effect of various amount geogrid content on the impact resistance of the OPS reinforced concrete slab of $20 \mathrm{~mm}$ thick [6].

The objective of the paper is to study the relationship of impact resistance of lightweight OPS geogrid reinforced concrete slab with different OPS content against the boundary condition and the geogrid orientation in its main direction and cross direction.

\section{Materials}

Oil palm shells (OPS) has unique physical properties, which make it a suitable replacement for conventional aggregate. OPS are naturally sized, hard and lighter than the conventional aggregates. The lightness in mass of oil palm shells make them a good substitute in the production of lightweight concrete. In the mix design of OPS-LWC (refer to TABLE 1), OPS to cement ratio by weight of $0.45,0.50$ and 0.60 are used.

Geogrid is made of high strength geosynthetic material which will be used as reinforcement in the lightweight oil palm shell concrete slab. The strength and flexibility of geogrid made it an ideal replacement of conventional steel reinforcement. The geogrid used in the experiment as reinforcement is Type A 160/50 having characteristic short term tensile strength of $160 \mathrm{kN} / \mathrm{m}$ in the main direction (MD) and $50 \mathrm{kN} / \mathrm{m}$ in the cross direction (CD). Each slab has one layer of reinforcement.

Ordinary Portland cement complying to ASTM Type I cement are used with a water cement ratio of 0.45 for all experimental design of concrete. The silica fume is supplied by EIKEM. It has the specific gravity of 2.2. The size of particle is $0.15 \mu \mathrm{m}$. It is grey in colour and slightly soluble in 
water. Silica fume used in the design mix is $5 \%$ of cement density. The amount of super plasticizer used will be equal to $2 \%$ weight of binder (silica fume and cement). The specific gravity of the superplasticizer used in this experiment is 1.12 .

TABLE 1 MIX DESIGN FOR OPS-LWC

\begin{tabular}{|l|c|c|c|}
\hline Constituents Materials & $\begin{array}{l}\text { Mix No 1 } \\
\text { (OPS:C } \\
\text { Ratio } \\
0.45)\end{array}$ & $\begin{array}{l}\text { Mix No 2 } \\
\text { (OPS:C } \\
\text { Ratio } \\
0.50)\end{array}$ & $\begin{array}{l}\text { Mix No 3 } \\
\text { (OPS:C } \\
\text { Ratio } \\
0.60)\end{array}$ \\
\hline Cement $\left(\mathrm{kg} / \mathrm{m}^{3}\right)$ & 530 & 530 & 530 \\
\hline Water $\left(\mathrm{kg} / \mathrm{m}^{3}\right)$ & 212 & 212 & 212 \\
\hline SilicaFume $\left(\mathrm{kg} / \mathrm{m}^{3}\right)$ & 26.5 & 26.5 & 26.5 \\
\hline Superplastizer $\left(\mathrm{kg} / \mathrm{m}^{3}\right)$ & 11.13 & 11.13 & 11.13 \\
\hline Sand $\left(\mathrm{kg} / \mathrm{m}^{3}\right)$ & 795 & 795 & 795 \\
\hline Oil Palm Shell $\left(\mathrm{kg} / \mathrm{m}^{3}\right)$ & 238.5 & 265 & 318 \\
\hline Cube Strength $\mathrm{f}_{\mathrm{cu}}, \mathrm{Mpa}$ & 28.4 & 27.5 & 26.0 \\
\hline
\end{tabular}

\section{Methodology}

The potential energy due to the drop body is absorbed as strain energy, generating stresses that causes cracks in the target element. The width, depth, length of the crack developed and its failure mode is associated with the intensity of the energy, the amount of energy absorbed and the properties of concrete. It is assumed that the total computed energy imparted is fully absorbed by the specimens. The relationship of potential energy of a dropweight projectile and the strain energy dissipated in cracks development is expressed as following formula as proposed by Kankam [7];

$\mathrm{N} * \mathrm{e}=\mathrm{Ru}^{*} 1 \mathrm{c}^{*} \mathrm{dc}^{*} \mathrm{wc}$

Where, $\mathrm{N}=$ No. of Blows, e = Energy per blow (Joules), $\mathrm{lc}=$ Total length of all cracks, dc = Maximum crack depth, $\mathrm{wc}=$ Maximum crack width, $\mathrm{Ru}=$ Ultimate crack resistance

Another dimensionless factor "impact crack resistance ratio ${ }^{\text {ee }}$ was also defined:

$$
\mathrm{Cr}=\mathrm{Ru} / \mathrm{fcu}
$$

Where, $\mathrm{Cr}=$ Impact crack resistance ratio, $\mathrm{fcu}=$ cube compressive strength of the concrete slab.

A total of 72 sample slabs of size $300 \mathrm{~mm} \times 300 \mathrm{~mm}$ with $20 \mathrm{~mm}, 30 \mathrm{~mm}$ and $40 \mathrm{~mm}$ thickness were casted and tested with 0.45 OPS (fcu=28.4 Mpa), 0.5 OPS (fcu=27.5 Mpa) and $0.60 \mathrm{OPS}$ (fcu= 26Mpa).

The study used a self-fabricated low velocity drop-weight impact test using a steel ball weighing $1.25 \mathrm{~kg}$ with drop height of $1000 \mathrm{~mm}$ impacting the specimen of size $300 \mathrm{~mm} \mathrm{x}$ $300 \mathrm{~mm}$ with thickness of $20 \mathrm{~mm}, 30 \mathrm{~mm}$, and $40 \mathrm{~mm}$ mounted on the steel rack frame with different boundary conditions. The slab specimen will constitute the three different amount of OPS/C ratio of $0.45,0.50$ and 0.60 . The slab specimen will also be subjected to different boundary conditions with geogrid placed with different orientation based on its main direction (MD) and cross direction (CD) facing the supports. At the first crack and ultimate (failure) crack, the total crack length, the crack width and the crack depth measured by filler gauge with its total numbers of blows recorded.

\section{Results and Discussion}

\section{A. Relationship between crack resistance against slab thickness}

There is a strong linear relationship between the crack resistance and slab thickness as shown in Fig 1a,1b and Fig $2 \mathrm{a}, 2 \mathrm{~b}$. The maximum first crack resistance for 0.45 OPS with $40 \mathrm{~mm}$ thick slab is $98.6 \mathrm{~N} / \mathrm{mm} 2$ and ultimate crack resistance is $633.9 \mathrm{~N} / \mathrm{mm} 2$. As the thickness increases, 0.45 OPS with a concrete cube strength $\mathrm{f}_{\mathrm{cu}}$ of $28.4 \mathrm{Mpa}$ has the highest crack resistance values as compare with 0.5 OPS $\left(\mathrm{f}_{\mathrm{cu}}=27.5 \mathrm{Mpa}\right)$ and 0.60 OPS $\left(\mathrm{f}_{\mathrm{cu}}=26.0 \mathrm{Mpa}\right)$.

The first crack resistance for 0.45 OPS with $20 \mathrm{~mm}$ thick slab using the geogrid, as compare to control (without geogrid) increase up to 3.1 times and its ultimate crack resistance increased by 15.2 times. The first crack resistance for 0.50 OPS with $20 \mathrm{~mm}$ thick slab as compare to control increase up to 3.8 times and ultimate crack resistance is 16.1 times. The first crack resistance ( 0.60 OPS with $20 \mathrm{~mm}$ thick slab) as compare to control increase up to 5.9 times and $(0.50$ (OPS0.6, 20mm thick slab)ultimate crack resistance is 20.1 times. The highest impact crack resistance ratio obtained is 22.3 for the 0.45 OPS with $40 \mathrm{~mm}$ thick slab.

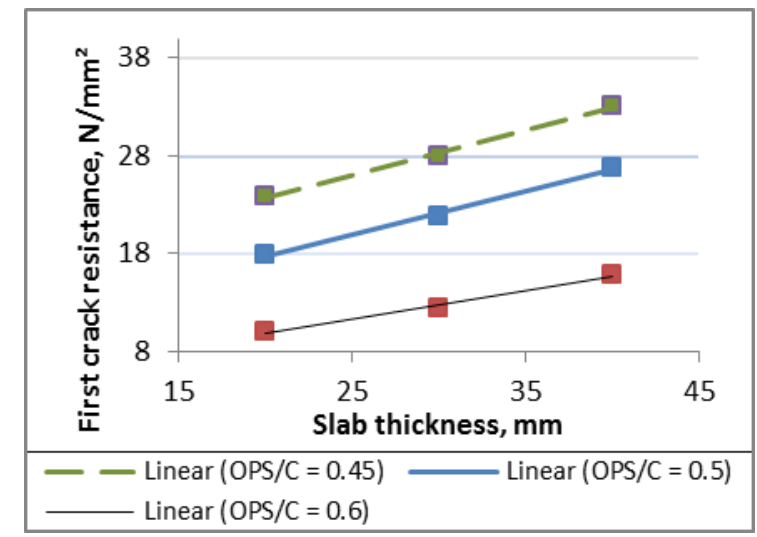

Figure 1a Ultimate Crack Resistance against Slab Thickness Control Sample (without geogrid) for Four (4) Support Boundary Condition

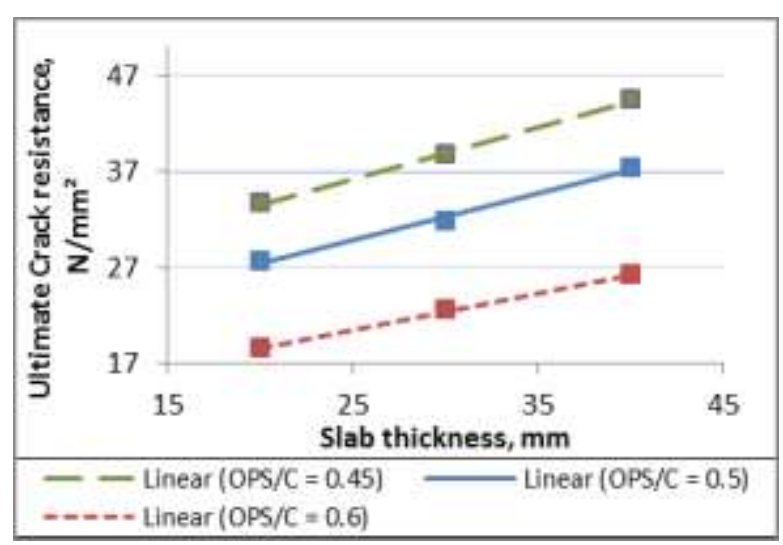

Figure 1b Ultimate Crack Resistance against Slab Thickness Control Sample (without geogrid) for Four (4) Support Boundary Condition 
Proc. of the Third Intl. Conf. on Advances in Civil and Structural Engineering - CSE 2015

Copyright $(\odot$ Institute of Research Engineers and Doctors, USA .All rights reserved.

ISBN: 978-1-63248-057-6 doi: 10.15224/ 978-1-63248-057-6-99

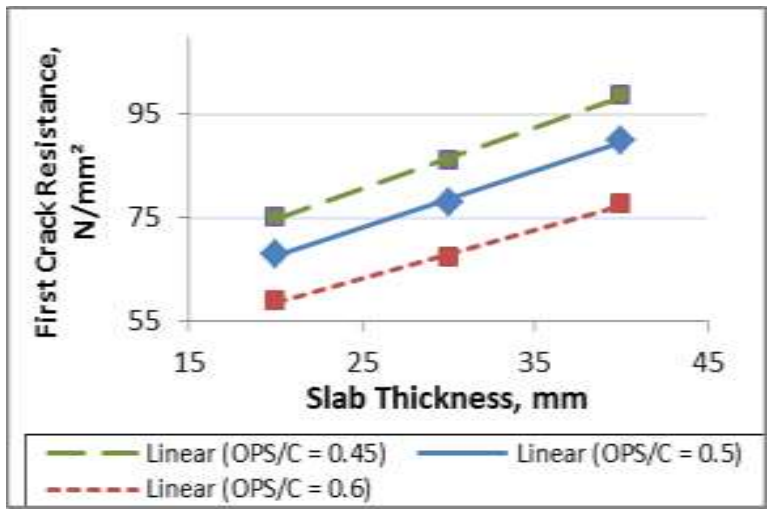

Figure 2a First Ultimate Crack Resistance against Slab Thickness with Geogrid for Four (4) Support Boundary Condition \

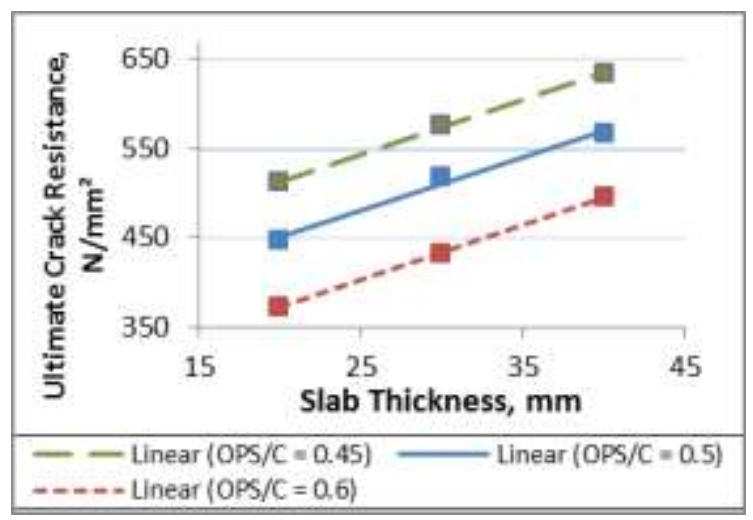

Figure 2b Ultimate Crack Resistance against Slab Thickness with Geogrid for Four (4) Support Boundary Condition

\section{B. Relationship between crack resistance against boundary conditions and geogrid orientations}

Generally the first and ultimate crack resistance increases with increasing number of supports at the boundary as shown in Fig $3 \mathrm{a}, 3 \mathrm{~b}$ and Fig. 4a,4b. The first crack resistance increase from $24.8 \%$ to $29.8 \% \mathrm{f}$ and from $26.8 \%$ to $40.6 \%$ for ultimate crack for four (4) supports as compare to two (2) supports boundary condition for various OPS/cement ratios.

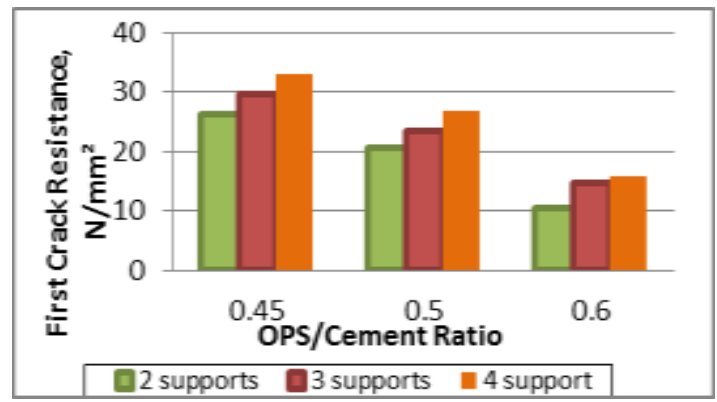

Figure 3a First Crack Resistance for Control Sample without Geogrid against Boundary Condition for $40 \mathrm{~mm}$ Thick Slab.

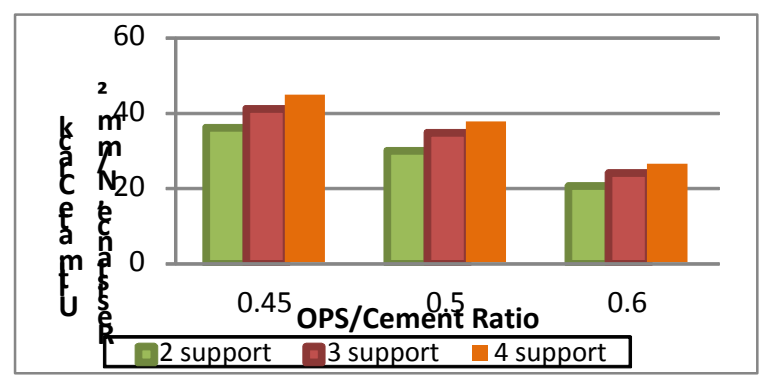

Figure 3b Ultimate Crack Resistance for Control Sample without Geogrid against Boundary Condition for $40 \mathrm{~mm}$ Thick Slab.

Comparing the first and ultimate crack resistance of the slab due to the orientation of the geogrid main direction with its cross direction, the increase varies only from $0.8 \%$ to $5.5 \%$. As such the orientation of the geogrid has minor significant to the crack resistance of the OPS concrete slab.

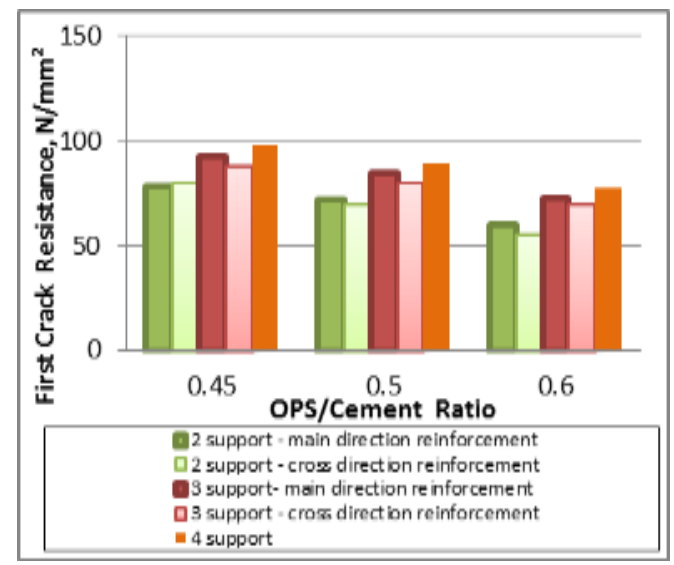

Figure 4a First Crack Resistance against Boundary Condition and Geogrid Orientation for $40 \mathrm{~mm}$ Thick Slab

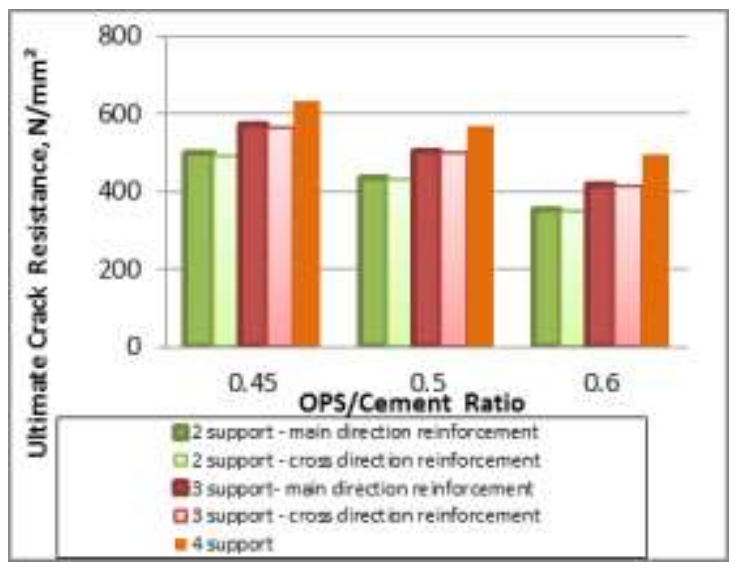

Figure 4b Ultimate Crack Resistance against Boundary Condition and Geogrid Orientation for $40 \mathrm{~mm}$ Thick Slab 


\section{v. Conclusions}

The following conclusions can be derived from the experimental results;

- The good linear relationship for the first and ultimate crack resistances against the slab thickness for various OPS/ cement ratio are obtained.

- The first and ultimate crack resistance increases with increasing number of supports at the boundary up to $29.8 \%$ for first crack resistance and up to $40.6 \%$ for ultimate crack for four (4) supports as compare to two (2) supports boundary condition for various OPS/cement ratio.

- The orientation of the geogrid, in its main direction as compare to its cross direction, has only a marginal effect on the crack resistance of the OPS concrete slab.

- OPS geogrid reinforced slab has a good impact resistance properties that can be utilized as a sustainable construction materials that have a maximum ultimate crack resistance of 633.9 $\mathrm{N} / \mathrm{mm} 2$

\section{Acknowledgment}

The authors express their gratitude to Civil Engineering Department, Universiti Tenaga Nasional, Malaysia who provided the funding for this study.

\section{References}

[1] Gopalartnam VS, Shah SP. Properties of fibre reinforced concrete subjected to impact loading. ACI J 1986;83(1):117-26.

[2] Mahmoud Nili, V. Afroughsabet. Combined effect of silica fume and steel fibers on the impact resistance and mechanical properties of concrete. International Journal of Impact Engineering 37(2010) 879 886Rao GV. Optimum designs for transmission line towers. Computers and Structures 1995;57:85-92.

[3] ACI Committee 544. State-of-the-art report on fiber reinforced concrete. ACI Committee 544 report 544.1R-96. Detroit: American Concrete Institute; 1996.

[4] Zakaria Che Muda, Kong Sih Ying, Salah F A Sharif, Lariyah Bte. Mohd Sidek, Nawfal S. Farhan, A Review - Local Failure On Concrete Target Due To Projectile Impact. International Journal of Science and Engineering Research (IJSER) Volume 4, Issue 1, January 2013.

[5] Zakaria Che Muda, Salah F A Sharif, Lariyah Bte. Mohd Sidek, Nawfal S Farhan, Impact Resistance Of Oil Palm Shells Lightweight Concrete Slab With Bamboo Fibers, International Journal of Science and Engineering Research (IJSER) Volume 4, Issue 1, January 2013.

[6] Zakaria Che Muda and Salah F A Sharif, Impact Behavior of Lightweight Oil Palm Shells Concrete Slab by Geogrid Reinforcement, International Journal of Scientific and Engineering Research (IJSER), Volume 3, Issue 11, November 2012.

[7] CK Kankam . Impact Resistance of palm kernel fibre-reinforced concrete pavement slab. J Ferrocement 1999;29(4):279-86. Oct

About Author (s):

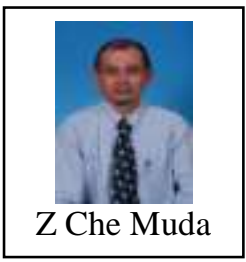

This paper show the impact resistance against various thickness, the effect of different boundary support conditions and reinforcement orientation on impact resistance of Light Weight Oil Palm Shells Reinforced Geogrid for concrete slab. 